\title{
The Intrinsic Value of Gold: An Exchange Rate-Free Price Index
}

\author{
Richard D. F. Harris \\ University of Exeter \\ Jian Shen \\ University of Exeter
}

July 2017

\begin{abstract}
In this paper, we propose a gold price index that enables market participants to separate the change in the 'intrinsic' value of gold from changes in global exchange rates. The index is a geometrically weighted average of the price of gold denominated in different currencies, with weights that are proportional to the market power of each country in the global gold market. Market power is defined as the impact that a change in a country's exchange rate has on the price of gold expressed in other currencies. We use principal components analysis to reduce the set of global exchange rates to four currency 'blocs' representing the U.S. dollar, the euro, the commodity currencies and the Asian currencies, respectively. We estimate the weight of each currency bloc in the index in an error correction framework using a broad set of variables to control for the unobserved intrinsic value. We show that the resulting index is less volatile than the USD price of gold and, in contrast with the USD price of gold, has a strong negative relationship with global equities and a strong positive relationship with the VIX index, both of which underline the role of gold as a safe haven asset.
\end{abstract}

Keywords: Gold price index; Commodities; Exchange rates; Cointegration; Error correction mechanism.

JEL codes: G12, G15, C58

Address for correspondence: Professor Richard D. F. Harris, Xfi Centre for Finance and Investment, University of Exeter Business School, Rennes Drive, Exeter EX4 4ST, UK, email: R.D.F.Harris@exeter.ac.uk. Dr Jane Shen, Xfi Centre for Finance and Investment, University of Exeter Business School, Rennes Drive, Exeter EX4 4PU, UK, email: js225@exeter.ac.uk. 


\section{Introduction}

The market for gold is one of the largest and most liquid in the world, surpassed only by the major currency pairs in terms of daily turnover. 1 The price of gold, like that of many commodities, is conventionally quoted in USD. However, gold is not exclusively a US asset and so the return from an investment in gold, when calculated using the quoted USD price, conflates the change in the value of gold with the change in the value of the USD. To illustrate this point, consider the change in the gold price between 30 March 2015 and 18 May 2015. The USD price rose from 1185.79 USD per ounce to 1228.05 USD per ounce, an increase of 3.56 percent. But to a UK investor, the price of gold fell from 800.99 GBP per ounce to 783.00 GBP per ounce, a decrease of 2.25 percent. The discrepancy arises because the USD depreciated against the GBP by more than the price of gold increased in USD terms. In this paper, we develop a gold price index, which when used to compute returns, reflects changes in the intrinsic value of gold independently of concurrent changes in global exchange rates. As an illustration of the use the index, we are able to establish that over the period described above, the intrinsic value of gold decreased by $0.54 \%$, and that the remaining changes in the price of gold in USD $(+3.02 \%)$ and GBP $(-1.31 \%)$ were due solely to exchange rate effects.

A number of market participants implicitly recognize this characteristic of the gold market and consider the gold price denominated in more than one currency. For example, the World Gold Council reports the price of gold not only in USD but also in other major currencies, and in the currencies of the major gold producing and consuming countries, where the non-USD prices are computed using the spot exchange rates against the USD. ${ }^{2}$ Similarly, the 2016 GFMS gold survey published by Thomson Reuters reports the price of gold in USD, EUR, JPY and INR, and also compares the USD price of gold with the USD trade-weighted exchange rate index. An alternative approach, and one that aims to uncover the underlying value of gold independent of exchange rate effects, is to construct a gold price index. The World

\footnotetext{
${ }^{1}$ See, for example, London Bullion Market Association (2011).

2 The World Gold Council reports the price of gold in USD, GBP, EUR, AUD, CAD, CHF, JPY, ZAR, INR, CNY, HKD and MXN.
} 
Gold Council reports three different price indices comprising (a) the major currencies weighted by 3-year GDP, (b) the currencies of the major consumer countries weighted by 3-year average demand for gold jewellery, bars and coins, and (c) the currencies of the major producer countries weighted by 3 -year average mine production. ${ }^{3}$ Other market participants decompose the change in the USD price of gold into the change in the value of the USD against a trade-weighted basket of currencies, and the residual change, which is interpreted as the change in the underlying value of gold. ${ }^{4}$ This latter approach amounts to computing a US trade-weighted index of the gold price denominated in different currencies.

Although such index-based approaches go some way towards removing the exchange rate component of the gold price, they do not properly reflect the intrinsic value of gold because they use arbitrarily defined weights that do not represent the actual impact that changes in individual exchange rates have on the quoted gold price. This is easily illustrated with a simple example. Suppose that there are two countries, A and B. We assume that the quoted gold prices in each country and the exchange rate between the two countries satisfy a basic no-arbitrage constraint. Suppose also that over some period, the demand and supply for gold are constant in both countries. For simplicity, we assume that changes in the exchange rate between the two countries do not affect the demand or supply of gold in either country, and that there is no inflation in either country. Suppose now that currency A depreciates against currency B. If gold were exclusive to country A, its price would fall in currency B but would remain unchanged in currency A, while if gold were exclusive to country B, its price would rise in currency A but remain unchanged in currency B. In the general case that gold is exclusive to neither country, the price of gold would increase in currency A and decrease in currency B. A number of important observations can be made. First, using any reasonable definition, the intrinsic value of gold should not have changed, since there has been no change in the demand or supply of gold in either country. Second,

\footnotetext{
${ }^{3}$ The currencies used in the three indices are USD, EUR, GBP, CAD, CHF and JPY (for the major currency index), INR, CNY, USD, TRY, SAR, IDR, AED, THB, VND, EGP, KRW, EUR and RUB (for the gold consumer index) and USD, ZAR, CNY, CAD and AUD (for the gold producer index).

${ }^{4}$ See, for example, the gold price index reported by the online precious metals retailer, Kitco (http://www.kitco.com/kitco-gold-index.html).
} 
in the general case where gold is exclusive to neither country, measuring the change in the price of gold in a single currency suggests that its value has either risen (if measured in currency A) or fallen (if measured in currency B), neither of which is correct. Third, the correct way to measure the change in the intrinsic value of gold is as a function of the price of gold in both currencies. Importantly, the appropriate weights in this function depend not on the relative sizes of the two countries (as measured by their GDP, for example) but on their influence in the global gold market, in other words, their relative market power.

The gold price index that we develop can be thought of as a geometric weighted average of the normalized real (i.e. inflation-adjusted) price of gold in different currencies. The weight of each currency is proportional to that country's market power in the global gold market as reflected in the impact that a change in the country's real exchange rate has on the real price of gold quoted in other currencies. We cast the relationship between the price of gold, exchange rates and a broad set of fundamental variables in a cointegration framework, in which we simultaneously model both the long run relationship between the price of gold and its determinants, and its short run dynamics. We use weekly data from 3 January 1995 to 22 February 2016 for 23 exchange rates against the GBP. ${ }^{5}$ In view of the very high correlations between many individual exchange rates, we use principal components analysis to extract the significant underlying exchange rate factors. Over the full sample, we find that there are four 'significant' principal components in real exchange rates, which are shown to represent the USD currency bloc, the commodity currency block, the EUR currency block, and the Asian currency bloc, respectively. The cointegration framework allows us to distinguish between the long run and short run elasticities of the price of gold with respect to exchange rates. In particular, the long run elasticity with respect to an exchange rate (or an exchange rate bloc) partially reflects structural changes and, in particular, the impact that a change in the exchange rate has on fundamentals through, for example, changes in production capacity or demand. In

\footnotetext{
${ }^{5}$ Below, we show that the choice of base currency is inconsequential. We choose the GBP as the base currency as, a priori, we would expect its market power in the global gold market to be close to zero (a prediction that we confirm empirically), and this facilitates the interpretation of the model parameters.
} 
contrast, the short run elasticity reflects the change in the gold price arising directly from changes in the exchange rate, i.e. changes in the price of gold that simply reflect 'translation' effects. It is these short run elasticities that are relevant for the construction of the gold price index.

We therefore first estimate the long run relationship between the real price of gold, real exchange rates and proxies for the non-exchange rate related fundamentals, including global equity and bond prices, the oil price and the level of the VIX index of implied volatility, and show that these variables are strongly cointegrated. The gold price has a negative long run relation with global equity and bond prices and a positive long run relation with the price of oil and the VIX index. Gold has a positive long run relationship with the USD bloc, the EUR bloc and the commodity currency bloc, but a somewhat weaker relationship with the Asian currency bloc. We then estimate the short run dynamics of the change in the gold price as a function of (1) changes in exchange rates, (2) changes in fundamentals and (3) the lagged error correction term that captures the deviation from long run equilibrium. The short run elasticities from this regression are then used as weights in the gold price index. Using the full sample to estimate the model, we show that the (normalized) weights on the USD bloc, the commodity bloc, the EUR bloc and the Asian currency bloc are about $21 \%, 47 \%, 30 \%$ and $2 \%$, respectively, reflecting the relative importance of these currency blocs for production, consumption and investment in the global gold market. We convert the real gold price index into a nominal USD gold price index to enable a comparison with the USD price of gold. We show that the nominal gold price index is less volatile than the USD gold price and, in contrast with the USD gold price, has a strong negative relationship with global equities and a strong positive relationship with the VIX index, both of which underline the role of gold as a safe haven asset. ${ }^{6}$

In the following section, we summarize the related literature. In Section 3, we present a stylized theoretical model of the gold price index. In Section 4, we describe the data and econometric methods used to estimate the weights of the gold price index, and

\footnotetext{
${ }^{6}$ By this we mean that its value tends to increase in times of financial market stress. This definition of a safe haven asset is taken from the literature (see, for example, Baur and Lucey (2010) and Erb and Harvey (2015).
} 
report the results of the empirical analysis. Section 5 reports the results of a subsample analysis while Section 6 summarizes our findings and offers some concluding comments.

\section{Related Literature}

Our research is most closely related to Sjaastad and Scacciavillani (1996), who develop a theoretical model of the relationship between exchange rates and the prices of internationally traded commodities. They show that the price of commodities such as gold can be written as a linear function of fundamentals and exchanges rates, with the coefficients on the exchange rates reflecting the relative market power that each country possesses. They consider the USD, JPY and DEM exchange rates, using the GBP as a base currency, and proxy the fundamental determinants of the price of gold by the US price level. They estimate the elasticities of the three currencies to be $28 \%$, $19 \%$ and 53\%, respectively, and conclude as a result that the global gold market is dominated by Europe. Sjaastad and Scacciavillani (1996) suggest that market power is derived from ownership of gold, rather than from production or consumption, since the latter represent very small annual flows relative to the stock of gold. For this reason, they exclude the major producing and consuming countries from their analysis. However, there are two problems with this assumption. First, there is no fundamental difference between stocks of above-ground gold (the largest of which are held by the US and Europe) and established reserves of below-ground gold (which are concentrated, not surprisingly, in the gold producing countries, with the largest being in Australia, South Africa and Russia ${ }^{7}$ ). Second, a country's market power is determined by the impact that it has on global gold prices, which is in turn related to its net contribution that it makes to global demand. What then determines market power? According to the World Gold Council, mining accounts for about two-thirds of the annual supply of gold, with the remaining one-third accounted for by the supply of scrap gold and the liquidation of gold investments that are held by both the private and public sector. ${ }^{8}$ A priori, therefore, we would expect the countries associated with the highest gold price elasticities to be those that have high production but relatively

\footnotetext{
${ }^{7}$ See US Geological Survey (2016).

${ }^{8}$ See World Gold Council (2011).
} 
low consumption, those that have high consumption with relatively low production, and those that are large net purchasers or sellers of investment gold.

Although the framework that Sjaastad and Scacciavillani (1996) use ostensibly bears some relation to ours, the focus of our research is different. Their aim is to establish the variation in the quoted gold price that can be attributed to fluctuations in exchange rates. In contrast, ours is to develop an index of the price of gold that is free of those exchange rate fluctuations. There are also a number of significant differences in the methodology that we adopt. First, we undertake the analysis in a cointegration framework, and are hence able to estimate both the long run elasticities, which reflect the impact the exchange rate changes might have on gold fundamentals, and short run elasticities, which capture the translation effects that are unrelated to gold fundamentals and are the relevant elasticities for the gold price index. Second, as part of the cointegration approach, we estimate the short run elasticities using an error correction model, and therefore include an error correction term that represents the deviation from the long run equilibrium between the gold price, exchange rates and other determinants of fundamental value. This allows us to more accurately estimate the model parameters, including the short run elasticities. Third, we control for a more comprehensive set of fundamental determinants. Fourth, we consider a much broader set of currencies, including all those that, a priori, could be expected to be influential in the global gold market.

Our work is also related to Pukthuanthong and Roll (2011), who note that it is commonly observed that depreciation of the USD against other currencies is typically associated with a rise in the USD price of gold. They state that "this is puzzling because it seems to imply something special about the relation between Dollars and gold. Dollar depreciation rather than the depreciation of another currency such as the Euro seems on the surface to bring a higher price of gold" (page 2070). They go on to show that, empirically, the price of gold in different currencies is actually positively correlated, and suggest that this is counterintuitive since it involves the price of gold rising (or falling) simultaneously in both appreciating and depreciating currencies. They demonstrate how this can happen using a simple decomposition of 
the covariance between the price of gold and the exchange rate. Importantly, however, they also suggest that this contradicts Sjaastad and Scacciavillani (1996), who state (as we do in the introduction, above) that the consequence of the law of one price is that if one currency depreciates against another, the price of gold will rise in the first currency and fall in the second currency, if fundamentals are unchanged. Of course, if fundamentals change, as they do in reality, the relationship between the price of gold denominated in different currencies will simply depend on the relative volatility of gold fundamentals and exchange rates. Pukthuanthong and Roll (2011) show (as we do below) that gold fundamentals are more volatile than exchange rates. Consequently, the documented positive correlation between the price of gold measured in different currencies is precisely what should be expected.

Clements and Fry (2008) analyze the relationship between exchange rates and commodity prices more broadly. The literature on 'commodity currencies' has focused on the impact that the changes in a commodity price have on the currencies of countries that are major producers of the commodity, with the implicit assumption concerning the direction of causality. Using a latent factor model comprising both a currency factor and a commodity factor, Clements and Fry (2008) analyze the link between the prices of various commodities and commodity currencies in order to ascertain the direction of causality. They show that while commodity prices are driven by exchange rate changes, there is no evidence that the reverse is true. In other words, certain currencies are 'commodity currencies' because they drive commodity prices, not because their value is driven by commodity prices. This is consistent with the framework that we use, in which commodity prices are a function of exchange rates as well as fundamentals. Note, however, that our specification permits the possibility that exchange rates are also a function of commodity prices since the cointegration framework that we use does not require us to specify the direction of long run causality.

Finally, our work is related to the large literature on modeling the time series properties of the gold price, both in levels and in first differences. Levin, Montagnoli and Wright (2006) use a cointegration framework to characterize the short and long 
run determinants of the gold price. They show that there is a positive long run relationship between the gold price and the US price level, as measured by the consumer price index, with approximately unit elasticity and so in the long run, gold provides a good hedge against domestic inflation for US investors. However, shocks to this relationship dissipate relatively slowly, taking about five years to eliminate two-thirds of the deviation. In the short run, the gold price fluctuates in response to changes in US inflation and inflation volatility, credit risk, the USD trade-weighted index and the gold lease rate. We also use the cointegration framework in order to estimate the long determinants of the gold price, but by using a wider range of variables including equity, bond and commodity prices and exchange rates, we are able to identify a much stronger long run relationship, with deviations from this relationship that dissipate much more rapidly.

Capie, Mills and Wood (2004) investigate the extent to which gold acts as a hedge against depreciation of the USD both internally (i.e. against inflation) and externally (i.e. against other currencies). Using daily data for the period 1971 to June 2002, and for sub-periods of economic and political turbulence, they show that gold is contemporaneously and negatively correlated with movements of both the USD effective exchange rate index and bilateral movements of the USD against the GBP, JPY, CHF and DEM, suggesting that it provides an effective hedge against fluctuations in the value of the USD. These results are consistent with our findings ${ }^{9}$, although by considering the relationship between the price of gold and each currency individually, they are unable to shed light on the relative importance of each currency in the global gold market, which is the focus of the current paper. More recent evidence casts doubt on the effectiveness of gold both as a hedge against inflation, and as a safe-haven asset (see, for example, Barro and Misra, 2016; Erb and Harvey, 2015), suggesting that such findings may be sample specific.

\footnotetext{
9 The coefficients on the exchange rates in their model are negative rather than positive since the exchange rates are measured as the foreign price of USD.
} 


\section{Theoretical Framework}

Suppose that there are $N$ countries. We denote the real price of gold in the currency of country $i$ in period $t$ by $P_{i, t}$, and the set of real exchange rates faced by country $i$ in period $t$ by the $N x 1$ vector, $\mathbf{S}_{i, t}$, where element $j=1, \ldots, N$ contains the real exchange rate between country $i$ and country $j$, denoted $S_{i j, t}$. We denote the fundamental value of gold at time $t$ by $F_{t}$. The fundamental value can be thought of as the component of the gold price that changes in response to changes in real net demand. Equivalently, the change in the fundamental value is the change in the gold price, measured in any currency, that would be observed if exchange rates were constant. We can write the change in the natural logarithm of the real price of gold in country $i$ as a function of two components, the first related to the change in fundamental value, and the second related to changes in global exchange rates:

$$
\Delta p_{i, t}=\Delta f_{t}+\boldsymbol{\theta}_{i}^{\prime} \Delta \mathbf{s}_{i, t}
$$

where $p_{i, t}=\ln P_{i, t}, \mathbf{s}_{i, t}$ is the $N x 1$ vector with elements $s_{i j, t}=\ln S_{i j, t}, f_{t}=\ln F_{t}$ and $\boldsymbol{\theta}_{i}$ is an $N \times 1$ vector of elasticities of the gold price with respect to each exchange rate. In particular, element $j$ of $\boldsymbol{\theta}_{i}$, is the elasticity of the change in the real price of gold in currency $i$, with respect to the change in the real exchange rate between currency $i$ and currency $j:{ }^{10}$

$$
\begin{aligned}
\boldsymbol{\theta}_{i} & =\frac{\partial \Delta p_{i, t}}{\partial \Delta \mathbf{s}_{i, t}} \\
& \approx \frac{\partial \Delta P_{i, t} / P_{i, t}}{\partial \Delta \mathbf{S}_{i, t} / \mathbf{S}_{i, t}}
\end{aligned}
$$

where the division in the denominator represents element-by-element division. The vector of elasticities, $\boldsymbol{\theta}_{i}$, is unconstrained and so equation (1) has very little economic

\footnotetext{
${ }^{10}$ Element $i$ of $\mathbf{S}_{i, t}$ is equal to one by construction, and the corresponding element of $\mathbf{s}_{i, t}$ is equal to zero. As a consequence, without imposing further restrictions, element $i$ of $\boldsymbol{\theta}_{i}$ is not identified.
} 
content. However, under the law of one price, we can show that the vector of elasticities is independent of the currency in which the gold price is measured. Consider the difference in the change in the real price of gold measured in currencies $i$ and $j, \Delta p_{i, t}-\Delta p_{j, t}$. Using (1), and noting that $\mathbf{s}_{j, t}=\mathbf{s}_{i, t}-\mathbf{1} s_{i j, t}$, where $\mathbf{1}$ is an $N \mathrm{x} 1$ vector of $1 \mathrm{~s}$, this is given by

$$
\begin{aligned}
\Delta p_{i, t}-\Delta p_{j, t} & =\boldsymbol{\theta}_{i}^{\prime} \Delta \mathbf{s}_{i, t}-\boldsymbol{\theta}_{j}^{\prime} \Delta \mathbf{s}_{j, t} \\
& =\boldsymbol{\theta}_{i}^{\prime} \Delta \mathbf{s}_{i, t}-\boldsymbol{\theta}_{j}^{\prime}\left(\Delta \mathbf{s}_{i, t}-\mathbf{1} \Delta s_{i j, t}\right) \\
& =\left(\boldsymbol{\theta}_{i}-\boldsymbol{\theta}_{\mathbf{j}}\right)^{\prime} \Delta \mathbf{s}_{i, t}+\boldsymbol{\theta}_{j}{ }^{\prime} \mathbf{1} \Delta s_{i j, t}
\end{aligned}
$$

Under the law of one price, $\Delta p_{i, t}-\Delta p_{j, t}=\Delta s_{i j, t}$ and so we have

$$
\left(\boldsymbol{\theta}_{i}-\boldsymbol{\theta}_{j}\right)^{\prime} \Delta \mathbf{s}_{i, t}+\boldsymbol{\theta}_{j}^{\prime} \mathbf{1} \Delta s_{i j, t}=\Delta s_{i j, t}
$$

which, collecting terms, can be written as

$$
\left(\boldsymbol{\theta}_{i}-\boldsymbol{\theta}_{j}\right)^{\prime} \Delta \mathbf{s}_{i, t}=\left(1-\boldsymbol{\theta}_{j}^{\prime} \mathbf{1}\right) \Delta s_{i j, t}
$$

For this to hold for all $i, j$ and $t$, we must have $\boldsymbol{\theta}_{i}=\boldsymbol{\theta}_{j}=\boldsymbol{\theta}$ and $\boldsymbol{\theta}^{\prime} \mathbf{1}=1$. Thus, under the law of one price, the vector of elasticities is identical for each country, and the sum of the elasticities is equal to unity. We can therefore write the change in the real price of gold in country $i$ as:

$$
\Delta p_{i, t}=\Delta f_{t}+\boldsymbol{\theta}^{\prime} \Delta \mathbf{s}_{i, t}
$$

Using a somewhat different framework that is based on a model of global market clearing, Sjaastad and Scacciavillani (1996) show that the elasticities, $\boldsymbol{\theta}$, are proportional to the market power of each country in the global gold market. These elasticities are unobserved but in the next section we estimate them empirically. 
The fundamental value of gold can be written as a weighted index of the real price of gold in the $N$ currencies, where the weights are given by the elasticities, $\boldsymbol{\theta}$. Rearranging (6), we have:

$$
\Delta f_{t}=\Delta p_{i, t}-\boldsymbol{\theta}^{\prime} \Delta \mathbf{s}_{i, t}
$$

Noting that $\Delta p_{i, t}=\Delta p_{j, t}+\Delta s_{i j, t}$, we can write $\Delta f_{t}$ as a weighted average of the change in the real price of gold in each of the $N$ currencies:

$$
\Delta f_{t}=\boldsymbol{\theta}^{\prime} \Delta \mathbf{p}_{t}
$$

where $\mathbf{p}_{t}$ is the $N x 1$ vector of $\log$ real gold prices, $p_{j, t}$. In levels, we have

$$
f_{t}=k+\boldsymbol{\theta}^{\prime} \mathbf{p}_{t}
$$

where $k$ is an arbitrary constant of integration that uniquely defines the index. Taking the exponent of both sides of Equation (9) yields

$$
F_{t}=K \prod_{j=1}^{N} \mathrm{P}_{j, t}^{\theta_{j}}
$$

where $K=e^{k}$. To define the index, we set $K=1 / \prod_{j=1}^{N} \mathrm{P}_{j, 0}^{\theta_{j}}$, and so we have

$$
\begin{aligned}
F_{t} & =\frac{1}{\prod_{j=1}^{N} \mathrm{P}_{j, 0}^{\theta_{j}}} \prod_{j=1}^{N} P_{j, t}^{\theta_{j}} \\
& =\prod_{j=1}^{N}\left(\frac{P_{j, t}}{P_{i, 0}}\right)^{\theta_{j}}
\end{aligned}
$$

Thus the fundamental value can be thought of as an index representing the weighted geometric average of the real price of gold in each of the $N$ currencies (in index form), with weights that are proportional to the market power of each country in the global 
gold market. As such, it is analogous to the definition of the real effective exchange rate of one currency against an aggregate of the other $N-1$ currencies (reported by the IMF, for example) with weights determined by the share of international trade for each country. Here we define the effective exchange rate of gold against an aggregate of all $N$ currencies, with weights determined by the market power of each country. The index is a measure of the fundamental value of gold in real terms. That is to say, a change in the index value reflects a change in the global net demand of gold by volume. However, we can also compute the corresponding nominal fundamental value index for a particular currency:

$$
F_{t}^{n}=F_{t} \bar{P}_{i, t}
$$

where $F_{t}^{n}$ is the nominal fundamental value and $\bar{P}_{i, t}$ is the general price level in country $i$. In the following section, we estimate the market power weights, and derive the resulting real and nominal gold price indices.

\section{Empirical Analysis}

\subsection{Data}

We use weekly data from 13 February 1995 to 22 February 2016, which represents the longest common sample available for the variables used in the analysis. All data are obtained from Datastream. We use the London Bullion Market gold price (Datastream code GOLDBLN) and WM/Reuters exchange rates. To compute the real price of gold and real exchange rates, we use each country's monthly or quarterly consumer price index, obtained from the IMF and linearly interpolated to yield weekly values. Following Sjaastad and Scacciavillani (1996), we use the GBP as a base currency for the price of gold and for the exchange rates since the coefficient on the GBP is expected to be close to zero, a priori, and indeed we show this to be the case empirically. ${ }^{11}$ Our initial sample comprises the exchange rates of 23 currencies

\footnotetext{
${ }^{11}$ As noted above, the choice of base currency (for both the exchange rates and the price of gold) is immaterial. In particular, converting the gold price and all exchange
} 
against the GBP. ${ }^{12}$ The currencies represent not only the major economies (CHF, EUR, JPY, USD), but also the most important countries in the gold market in terms of mine output (AUD, CAD, CNY, GHS, PGK, IDR, MXN, PEN, RUB, ZAR), scrap processing (EGP, KRW, TRY) and demand for jewellery, bullion and coins (BRL, HKD, INR, SAR, THB, VND). ${ }^{13}$

Inevitably, there is a high degree of collinearity among many of the real exchange rates, owing to either structural similarities or the use of managed exchange rate systems. As is well known, while such collinearity does not invalidate the estimation of the model, it complicates the interpretation of the estimated coefficients by inflating the associated standard errors, making it difficult to distinguish the marginal effects of individual exchange rates. Moreover, the econometric framework that we use precludes the use of such a large set of variables. We therefore consider two approaches to reduce the dimensionality of the data. First, we reduce the full sample of 23 currencies to a subset of seven currencies, namely AUD, EUR, JPY, KRW, RUB, TRY, and USD. This reduced set of currencies was chosen to eliminate any exchange rate pairs that have a correlation in excess of 0.4 , but while retaining JPY (which has a correlation with USD of just over 0.5) owing to its status as a major currency). Second, we use principal components analysis (PCA) to extract the common sources of variation in the first differences of the $23 \log$ real exchange rates.

rates into an alternative base currency at the quoted exchange rate (i.e. imposing triangular no-arbitrage) and re-estimating the regression yields identical parameter estimates by construction. The only difference between the two regressions is that the parameter associated with the base currency in each case is not identified. However, since the sum of the exchange rate sensitivities must be equal to unity, the missing sensitivity is easily recovered.

12 The 23 currencies are AUD (Australian dollar), BRL (Brazilian real), CAD (Canadian dollar), CHF (Swiss franc), CNY (Chinese yuan), EGP (Egyptian pound), EUR (European euro ), GBP (British pound), GHS (Ghanian cedi), HKD (Hong Kong dollar), IDR (Indonesian rupiah), INR (Indian rupee), JPY (Japanese yen), KRW (Korean won), MXN (Mexican peso), PEN (Peruvian sol), PGK (Papua New Guinea Kina), RUB (Russian ruble), SAR (Saudi riyal), THB (Thai baht), TRY (Turkish lira), USD (United States dollar), VND (Vietnamese dong) and ZAR (South African rand).

${ }^{13}$ These currencies are the same as those used in the World Gold Council indices with the exception of the AED, for which insufficient data on consumer prices is available to be included in our sample. However, the AED is very highly correlated with the USD, and so its exclusion from the analysis has very little impact. 
Using the Kaiser criterion, there are four 'significant' principal components (i.e. those that have an associated eigenvalue greater than unity), which together explain about 69 percent of the total variation in the 23 exchange rates. The results of principal components analysis are reported in Table 1. Inspection of the first four eigenvectors reveals that they each have a natural interpretation. In particular, PC1 has the largest weights on the USD and currencies that are either pegged to the USD or highly correlated with it (e.g. CNY, EGP, HKD, INR, PEN, SAR, THB and VND) and can therefore be thought of as representing the USD bloc. PC2 has the largest weights on AUD, BRL, CAD, MXN, TRY and ZAR, and can be thought of as representing the commodity currency bloc. PC3 has the largest weights on the EUR and CHF, and thus represents the EUR bloc. PC4 has relatively high weights on IDR, KRW, THB and, to a lesser extent, JPY, and can therefore be thought of as representing the Asian currency bloc. A number of currencies naturally belong to more than one bloc, most notably CAD (which has a relatively high weight in both PC1 and PC2) and JPY (which has a relatively high weight in PC1, PC3 and PC4). The use of PCA avoids the need to arbitrarily assign such currencies to one bloc or the other, and instead allocates a fraction of the variation in the currency to each bloc. For the cointegrating regression, which is specified in terms of the levels of the variables, rather than first differences, the direct application of PCA is not valid since the exchange rates are non-stationary. Instead, we cumulate each of the first four principal components of the first differences of the exchange rates. ${ }^{14}$

[Table 1]

The fundamental variables are drawn from the literature and motivated by the role that gold is purported to have as a safe haven asset (see, for example, Malliaris and Malliaris, 2015; Erb and Harvey, 2015; Barro and Misra, 2016). We include the MSCI world equity price index (wequity), the Citigroup world bond price index

\footnotetext{
14 To check the robustness of this approach, we also experimented with using an equally weighted index of the full sample of 23 exchange rates, the significant principal components of the exchange rates in levels (ignoring issues arising from their non-stationarity), and the reduced sample of seven exchange rates. All three approaches yield results that are very similar to the use of the cumulated principal components of the first difference of the exchange rates.
} 
(wbond), the price of Brent crude oil (oil) and the level of the VIX index (vix) ${ }^{15,16}$ For each of the fundamental variables that is measured in currency terms (i.e. wequity, wbond and oil), we first compute the real value of the variable in each of the seven currencies of the reduced sample, deflating it by the respective CPI. We then construct a geometrically weighted average index of these values across the seven currencies, with the weights of the gold price index estimated using equation (14) below. These weights are obtained iteratively, with the initial weights for the fundamental variable indices set to be equal. ${ }^{17}$

Table 2 reports the correlation matrix between the price of gold, the fundamental variables, the reduced sample of seven exchange rates and the first four principal components of the full sample of 23 exchange rates, all measured in logarithmic differences. The change in the gold price has a negative correlation with equity returns and a very weak positive correlation with bond returns, the change in the oil price and the change in the level of VIX. The strongest correlations are with the exchange rate changes, and the principal components of the exchange rate changes. Table 3 reports summary statistics for the data. The principal components have zero mean by construction, and are normalized to have unit Euclidean length. There is considerable variation in the volatility of exchange rates, with KRW, RUB and TRY being the most volatile.

[Tables 2 and 3]

\subsection{Methodology}

Equation (1) defines the relationship between the change in the price of gold measured in the base currency, the change in the fundamental value of gold and the change in each of the exchange rates. However, we start by estimating the relationship

15 The Datastream codes for the four variables are MSWRLD\$, SBWGUII, LCRINDX, and CBOEVIX, respectively.

${ }^{16}$ Similar results were obtained using 10-year and 3-month US Treasury rates, deflated by US CPI inflation, in place of the bond price index.

17 The weights converge very rapidly and in the results reported below, we use two iterations. 
between the real gold price, fundamental variables and real exchange rates in levels. The variables involved in this relationship are non-stationary and thus, if such a relationship is to make sense, they should be cointegrated, in which case deviations from this relationship should determine the short run dynamics of the variables in the form of an error correction model. ${ }^{18}$ Our analysis therefore proceeds in two stages. First, we estimate the following regression in levels:

$$
p_{i, t}=\alpha_{0}+\delta \tau+\boldsymbol{\alpha}_{1}^{\prime} \mathbf{z}_{t}+\boldsymbol{\alpha}_{2}^{\prime} \mathbf{s}_{i, t}+\varepsilon_{t}
$$

where $p_{i, t}$ is the real GBP price of gold, $\mathbf{z}_{t}$ is the $4 \times 1$ vector of fundamental variables (wequity, wbond, oil and vix), $\mathbf{s}_{i, t}$ is either the $7 \times 1$ vector of $\log$ real exchange rates or the $4 \times 1$ vector of the cumulated principal components of the first difference of the 23 $\log$ real exchange rates, $\tau$ is a time trend, $\alpha_{0}, \delta, \boldsymbol{\alpha}_{\mathbf{1}}$ and $\boldsymbol{\alpha}_{\mathbf{2}}$ are parameters and $\varepsilon_{t}$ is a zero-mean random error. We estimate the cointegrating relationship by OLS. If the variables in equation (13) are cointegrated then the error term should be stationary, which we test using the simulated Engle-Granger critical values of MacKinnon $(2010) .^{19}$

The second step is to estimate an error correction model for the change in the gold price, given by:

\footnotetext{
${ }^{18} \mathrm{We}$ do not report the results of the stationarity tests, but they are available on request.

${ }^{19}$ The Engle-Granger methodology that we use is appropriate when there is a single cointegrating vector $(\mathrm{CV})$. To check the validity of this assumption, we applied the Johansen trace test based on a vector error correction model (VECM) specification. For the model using principal components (on which the main results are based), using a VECM with a lag length of one (selected by the Schwartz Bayesian criterion) and including an unrestricted constant in the VECM (which allows for a linear trend in the level of the variables), the Johansen trace test rejected the null hypothesis of zero CVs against the null hypothesis of one CV (trace statistic of 258.6 vs. the 5\% critical value of 192.9), but did not reject the null hypothesis of one CV against the alternative hypothesis of two CVs (trace statistic of 147.4 vs. the $5 \%$ critical value of 156.0). We therefore conclude that there is a single $\mathrm{CV}$, justifying the use of the Engle-Granger procedure. This finding is robust to the choice of lag length in the VECM and alternative specifications of the deterministic constant and trend. The full results of this analysis are available on request from the authors.
} 


$$
\Delta p_{i, t}=\beta_{0}+\boldsymbol{\beta}_{1}^{\prime} \Delta \mathbf{z}_{t}+\boldsymbol{\beta}_{2}^{\prime} \Delta \mathbf{s}_{i, t}+\beta_{3} \hat{\varepsilon}_{i, t-1}+e_{i, t}
$$

where $\hat{\varepsilon}_{i, t}=p_{i, t}-\hat{\alpha}_{0}-\widehat{\boldsymbol{\alpha}}_{1}^{\prime} \mathbf{z}_{t}-\widehat{\boldsymbol{\alpha}}_{2}^{\prime} \mathbf{s}_{\boldsymbol{i}, \boldsymbol{t}}$ is the error correction term from the estimated cointegrating regression given by (13), $\beta_{3}$ is the speed of adjustment coefficient and $\Delta \mathbf{s}_{i, t}$ is either the $7 \times 1$ vector of the first differences of the log real exchange rates or the $4 \times 1$ vector of the principal components of the first differences of the 23 log real exchange rates. The parameter vector $\boldsymbol{\beta}_{2}$ represents the short run elasticities of the gold price with respect to the exchange rates. We estimate the ECM given by (14) by OLS. For the specification with the seven individual exchange rates, we additionally estimate a constrained version of the ECM given by (14) in which we impose the restrictions that the short run elasticities are non-negative and sum to unity. ${ }^{20}$ The constrained ECM is estimated by Nonlinear Least Squares (NLS). For all three models, we report tests for first order serial correlation and heteroscedasticity.

\subsection{Estimation Results}

Table 4 reports the results of estimating the cointegrating regression given by Equation (13) by OLS, with the estimated cointegrating vector in Panel A and the Zstatistic for the Engle-Granger test for the null hypothesis of no cointegration in Panel B. Results are reported for the models based on both the seven individual exchange rates and the first four principal components of the full set of 23 exchange rates. To investigate the robustness of our results, we separately estimate the latter model using the first one, two, three and four principal components. The null hypothesis of no cointegration is rejected at the $10 \%$ level using the seven individual currencies, at the $5 \%$ level using the first one, two or three principal components, and at the $10 \%$ level using the first four principal components, suggesting that the gold price is cointegrated with the fundamental variables and the exchange rates. The gold price has a negative long run relation with global equity and bond prices and a positive long run relation with the VIX index and, in four of the five cases, with the price of oil and

${ }^{20}$ This forces the coefficient on the GBP (the base currency) to be exactly zero. It is only possible to estimate constrained versions of the ECM that include individual exchange rates since the principal components of the exchange rates are normalized to have unit Euclidean length. 
the. Gold has a positive long run relationship with the USD bloc, the EUR bloc and the commodity currency bloc, but a somewhat weaker (and negative) relationship with the Asian currency bloc. In the remaining analysis, we use the error correction term from the model with four principal components, although almost identical results are obtained with three principal components.

\section{[Table 4]}

Table 5 reports the results of estimating the error correction model given by Equation (14). The specification in Column 1 includes the reduced set of seven exchange rates with no constraints on the coefficients. The model explains 22 percent of the variation in the change in the real gold price. The coefficient on $\Delta$ wequity is significantly negative, suggesting that after controlling for the exchange rate effects, gold is negatively correlated with global equity markets, supporting its role as a safe haven asset. The coefficient on $\Delta w b o n d$ is also positive, although not significant. The coefficient on $\Delta o i l$ is significantly positive, but the coefficient on $\Delta v i x$ is insignificantly different from zero, suggesting that uncertainty in the economy is perhaps captured through the change in equity prices or in the price of oil. The coefficient on the error correction term is -0.046 , and significant at the one percent level. This is substantially larger than the value of -0.019 reported by Levin, Montagnoli and Wright (2006) using monthly data. This is perhaps explained by the fact that the cointgerating relationship given by (13) includes a larger set of fundamental variables, and hence better captures the long run determinants of the price of gold. The sum of the coefficients is equal to 0.984 , so the implied coefficient on GBP is 0.016 , which is close to its assumed value of zero, particularly given that this specification only includes seven of the 23 currencies. The coefficients on the exchange rates are positive except for KRW (-0.024) and TRY (-0.022). The largest weight is on AUD, followed by EUR, JPY and USD.

The specification in Column (2) imposes the constraint that the coefficients on the exchange rates are non-negative and sum to unity. The constrained model is estimated by nonlinear least squares. Imposing the constraint has no measurable impact on the 
overall explanatory power of the model, and only the coefficient on global bond prices is affected, although it remains insignificantly different from zero. The model again suggests that the gold market is dominated by the AUD, followed by the EUR, JPY and the USD, and currencies that are correlated with these but not included in the model. The specification in Column 3 replaces the individual exchange rate changes with their first four principal components, which were shown above to represent the USD bloc, the commodity bloc, the EUR block and the Asian bloc, respectively. The explanatory power of the model is enhanced by including information about the wider set of currencies, with the R-squared rising marginally to $24.5 \%$. The first three principal components are positive and highly significant, while the fourth principal component is positive but statistically insignificant and small in magnitude. Thus, while the Asian currencies evidently share certain dynamic characteristics that are distinct from those of other currencies, these dynamics do not appear to be important for the global gold market. The principal components are normalized so that they have unit Euclidean length, and so their coefficients do not have the same interpretation as those on individual exchange rates. However, assuming that the weight on the GBP is zero (as is suggested, at least approximately, by the unconstrained model in Column (1)), re-normalizing the coefficients on the first four principal components yields weights of $21.1 \%, 46.9 \%, 30.0 \%$ and $1.9 \%$ on the USD bloc, the commodity bloc, the EUR bloc and the Asian currency bloc, respectively. Our findings thus suggest that the global gold market is dominated by the commodity bloc countries by a considerable margin, followed by the EUR and USD blocs, and that the Asian currency bloc does not play a significant role in the gold market.

[Table 5]

It is useful to compare our results to those reported by Sjaastad and Scacciavillani (1996), who using a different approach estimate the market power associated with the DEM, JPY and USD, also using the GBP as the base currency, but include only the world price level to capture fundamentals. They estimate the weights on the three currencies to be $53.4 \%, 19.0 \%$ and $27.6 \%$, respectively. We also find a very significant role for the EUR and USD blocs, but our results suggest that by excluding 
the major commodity currencies, the sample considered by Sjaastad and Scacciavillani (1996) represents only a little over half of the global gold market.

\section{The Gold Price Index}

We now calculate the gold price indices that are implied by the three ECMs estimated above. For the models that use the individual exchange rates (i.e. Columns 1 and 2), it is a straightforward matter of computing the geometric weighted average index given by Equation (11). For the model that uses the principal components (i.e. Column 3), we first calculate the weights on the individual exchange rates that are implied by the four principal components and their estimated coefficients, and then normalize these weights so that they sum to unity. These normalized weights are then used to compute the index. All three indices are rebased to be equal to 100 at the beginning of the sample. The indices, which are plotted in Figure 1, are very close to each other, with only very minor differences between them.

\section{[Figure 1]}

We also calculate the nominal gold price index given by Equation (12) using the US $\mathrm{CPI}$ to inflate the real gold price index. Figure 2 plots the real and nominal gold price indices (both based on the principal components model), and the USD gold price, all based to 100 on 13 February 1995. The difference between the real index and the nominal index is equal to the cumulative impact of the US price level, while the difference between the USD price of gold and the nominal index reflects the impact of exchange rate changes. The three series share a number of characteristics and, over the sample, they follow the same broad trajectory, peaking in August 2011. It is clear from the figure that this was caused by a combination of an increase in the fundamental value of gold (in real terms) and an increase in the general US price level, but further exacerbated by a deterioration in the value of the USD against other currencies. We can also see that, despite a similar broad trajectory, there are significant deviations between the USD price of gold and the gold price index, with sustained periods in which the USD price fell but the gold price index rose, or vice 
versa. For example, over the last two years of the sample, while the USD price of gold fell by $9.6 \%$, the fundamental value of gold rose by $13.0 \%$ in real terms and by $14.0 \%$ in nominal terms.

[Figure 2]

To isolate the impact of exchange rate changes on the price of gold, in Figure 3 we report the ratio of the USD gold price to the nominal gold price index both based to 100 on 13 February 1995. This ratio can be thought of as an index of the weighted value of the USD against other currencies, with weights proportional to the influence of those currencies in the gold market. The lower the value of this ratio, the higher the relative value of the USD. Most notable, perhaps, is the sharp reduction in the ratio during the financial crisis of 2008, reflecting the safe haven characteristic of the USD during times of market turbulence. The longer run changes in the value of the USD (such as its steady strengthening since 2011) are also evident.

\section{[Figure 3]}

\section{Characteristics of the Gold Price Index}

Table 6 reports summary statistics of the log changes in the nominal gold price index and the USD price of gold. In particular, it reports the mean, standard deviation, minimum and maximum, as well as correlations with the log changes in the world equity and bond indices and the oil price, all measured in USD, and with the log change in the VIX index. The index has a similar mean return, but is less volatile than the USD gold price. The gold price index has a strong and statistically significant negative correlation with global equities, emphasizing its role as a safe haven asset. In contrast, the USD price of gold is positively correlated with global equities, conflating the role of gold as a safe haven asset with that of the USD. Similarly, while the VIX index is approximately uncorrelated with the USD price of gold, it is strongly positively correlated with the gold price index, showing that the value of gold increases during times of market uncertainty as measured by the implied volatility of 
US equity returns. The gold price index has a weaker correlation with both global bond prices and the oil price.

\section{[Table 6]}

\section{Sub-Period Analysis}

To investigate the robustness of our findings, and to explore how influence in the global gold market has changed over time, Table 7 reports results of estimating the error correction model based on the first four principal components of the 23 exchange rates for three equal sub-periods. The table also reports the Z-statistic to test the null hypothesis of no coinegration in the Engle-Granger first stage regression. The evidence of cointegration among the variables is very strong in the second and third sub-periods (with significance levels lower than one percent), but only marginal in the first sub-period (with a significance level just over ten percent). In the ECM model itself, the error correction term is significant in all three sub-periods and the coefficient is larger in value than in the full sample. However, this partly reflects that the coefficient is estimated with much lower precision than in the full sample. The role of the control variables is somewhat unstable over the three sub-periods, and generally only significant in the final sub-period, i.e. in the period since the financial crisis. In contrast, exchange rate changes are an important determinant of the change in the gold price in all three sub-periods. In particular, the first three principal components (the USD bloc, the commodity bloc and the EUR bloc, respectively) are significant in all cases, and the fourth principal component (the Asian currency bloc) is highly significant in the third sub-period. However, the relative influence of the individual currency blocs has evidently evolved over time. In the first sub-sample (i.e. before the financial crisis of 2008), the gold market was dominated by the USD and EUR blocs, which is broadly consistent with the findings of Sjaastad and Scacciavillani (1996). In the second sub-period, which contains the financial crisis, the gold market was dominated by the EUR currency bloc, and to a lesser extent by the commodity currency bloc, with the influence of the USD bloc considerably reduced. In the final sub-period, the gold market has come to be dominated by the 
Asian currency bloc and the commodity currency bloc, followed by the USD and EUR blocs.

\section{[Table 7]}

\section{Conclusion}

Although the price of gold is invariably quoted in USD, it is not exclusively a US asset. Consequently, changes in the quoted price of gold conflate changes in the 'intrinsic' value of gold, i.e. changes in the price of gold that are caused by fluctuations in demand and supply, both with changes in the value of the USD against other currencies, and with changes in the US price level. In this paper, we propose a gold price index that enables market participants to separate these components of the change in the gold price. The index is a geometrically weighted average of the price of gold denominated in different currencies, with weights that are proportional to the market power of each country in the global gold market, which we estimate empirically. We cast the relationship between the price of gold, exchange rates and a broad set of fundamental variables in a cointegration framework, in which we simultaneously model both the long run relationship between the price of gold and its determinants, and its short run dynamics. In view of the very high correlations between individual exchange rates, we use principal components analysis to extract the significant underlying exchange rate factors. We show that the (normalized) weights on the USD bloc, the commodity bloc, the EUR bloc and the Asian currency bloc are about $21 \%, 47 \%, 30 \%$ and $2 \%$, respectively, reflecting the relative importance of these currency blocks for production, consumption and investment in the global gold market.

An accurate gold price index that properly reflects the underlying value of gold has a number of uses. First, it allows market participants and regulators to separate changes in the price of gold from changes in global exchange rates and, in so doing, to properly understand the role that gold plays in international financial markets. As an illustration of this point, gold is often considered to be a safe-haven asset, and for its 
value to rise in times of crisis. Yet the empirical evidence for this is mixed (see, for example, Smith 2001; Barro and Misra, 2016; Erb and Harvey, 2015). In our sample, the USD return from investing in gold has a weak positive correlation with global equity returns, casting doubt on gold's perceived status as a safe-haven asset. A plausible explanation for this is that while gold is a safe-haven asset, the USD is an even greater safe-haven asset and in times of crisis, the value of the USD rises by more than the value of gold (see Fatum and Yamamoto, 2016). Our gold price index allows us to confirm this hypothesis. Indeed, we show that while the USD gold price is positively correlated with equity returns, the gold price index is very significantly negatively correlated with equity returns, suggesting that when equity markets fall, the intrinsic value of gold does indeed rise. A second use of a gold index is to help investors to understand the dynamics of the gold price, which are otherwise potentially obscured by the dynamics of exchange rates. Such dynamics include momentum, return reversals and time-varying conditional volatility, for example. The gold price index allows one to study these characteristics of the intrinsic value of gold, separately from those of exchange rates. A third benefit that arises from being able to separate movements in the gold price from movements in exchange rates is that it may allow for more finely tuned hedging policies by market participants who want to protect themselves against future gold price volatility independently of volatility in the currency markets. Relatedly, the creation of a gold price index provides an opportunity for the introduction of derivative instruments that track the value of gold independently of exchange rates. Finally, we focus on gold because of the rather special role that it plays in the financial system as a store of wealth, in contrast with other commodities, and the size of the gold market also suggests that it warrants special attention. However, the approach that we develop is applicable to other commodities. Moreover, to the extent that the quoted prices of all financial assets are influenced by fluctuations in exchange rates, the approach could be usefully applied to other asset classes. 


\section{References}

Barro, R. J. and S. Misra, 2016, “Gold Returns”. Economic Journal 126, 1293-1317.

Baur, D., and B. Lucey, 2010. "Is Gold a Hedge or a Safe Haven? An Analysis of Stocks, Bonds and Gold." Financial Review 45, 217-229.

Beckers, S., and L. Soenen, 1984, "Gold: more attractive to non-US than to US investors?", Journal of Business Finance and Accounting 11, 107-112.

Capie, F., T. Mills and G. Wood, 2005, "Gold as a hedge against the US dollar", Journal of International Financial Markets, Institutions and Money 15, 343-352.

Clements, K., and R. Fry, 2008, "Commodity currencies and currency commodities", Resources Policy 33, 55-73.

Erb, C., and C. Harvey, 2015, “The Golden Dilemma”, Financial Analysts Journal 69, $10-42$.

Fatum, R., and Y. Yamamoto, 2016, "Intra-Safe Haven Currency Behavior During the Global Financial Crisis", Journal of International Money and Finance 66, 49-64.

Levin, E., A. Montagnoli and R. Wright, 2006, “The short and long run determinants of the price of gold", World Gold Council Research Report No 32.

London Bullion Market Association, 2011, Loco London Liquidity Survey: Gold Turnover Survey for Q1, 2011.

MacKinnon, J., 2010, “Critical Values for Cointegration Tests", Queen's Economics Department Working Paper No. 1227, Queen's University, Kingston, Ontario, Canada.

Malliaris, A., and M. Malliaris, 2015, "What drives gold returns? A decision tree analysis", Finance Research Letters 13, 45-53.

Pukthuanthong, K., and R. Roll, 2011, "Gold and the Dollar (and the Euro, Pound, and Yen)", Journal of Banking and Finance 35, 2070-2083.

Sari, R., S. Hammoudeh and B. Ewing, 2007, "Dynamic relations between oil and other commodity futures prices", Geopolitics of Energy 29, 1-12.

Sari, R., S. Hammoudeh and U. Soytas, 2010, "Dynamics of oil prices, precious metal prices, and exchange rates", Energy Economics 32, 351-362.

Sjaastad, L., and F. Scacciavillani, 1996, "The price of gold and the exchange rate", Journal of International Money and Finance 15, 879-897.

Smith, G., 2001, "The price of gold and stock price indices for the United states", World Gold Council. 
US Geological Survey, 2016, Mineral Commodity Summaries.

World Gold Council, 2011, Liquidity in the Global Gold Market. 


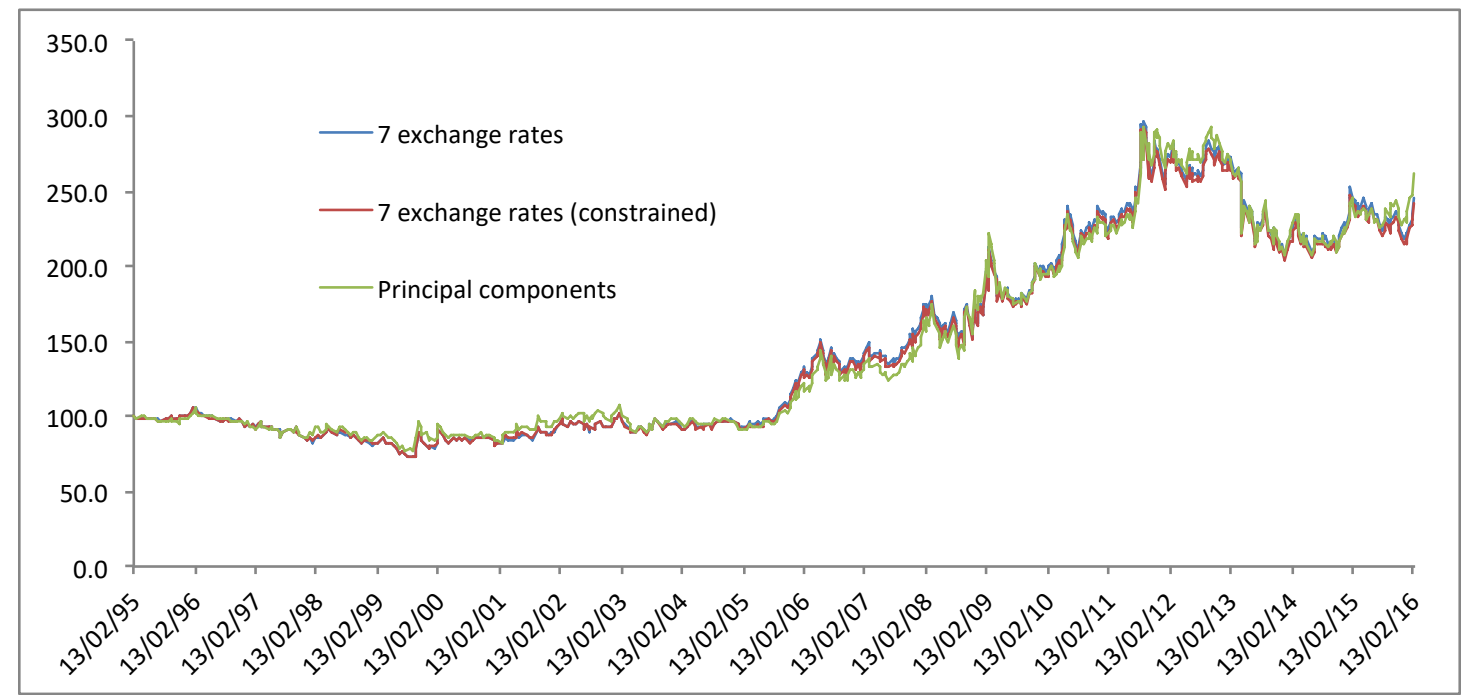

Notes: The figure plots the real gold price index calculated using the unconstrained model, the constrained model and the principal components model using Equations (13) and (14). All three series are rebased to 100 on 13 February 1995. 


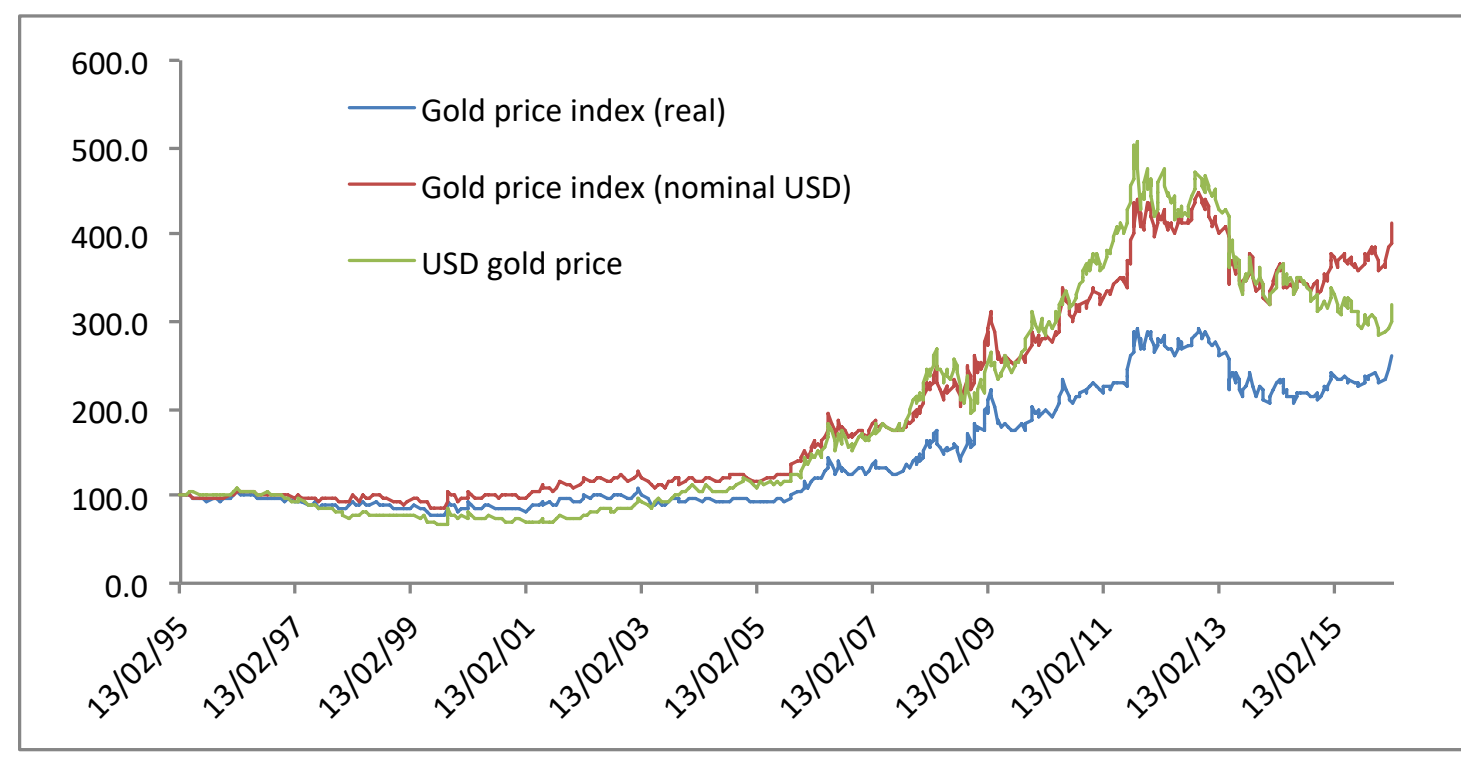

Notes: The figure plots the real and nominal gold price indices, estimated using the principal components model given by Equations (13) and (14), and the USD price of gold. All three series are rebased to 100 on 13 February 1995. 


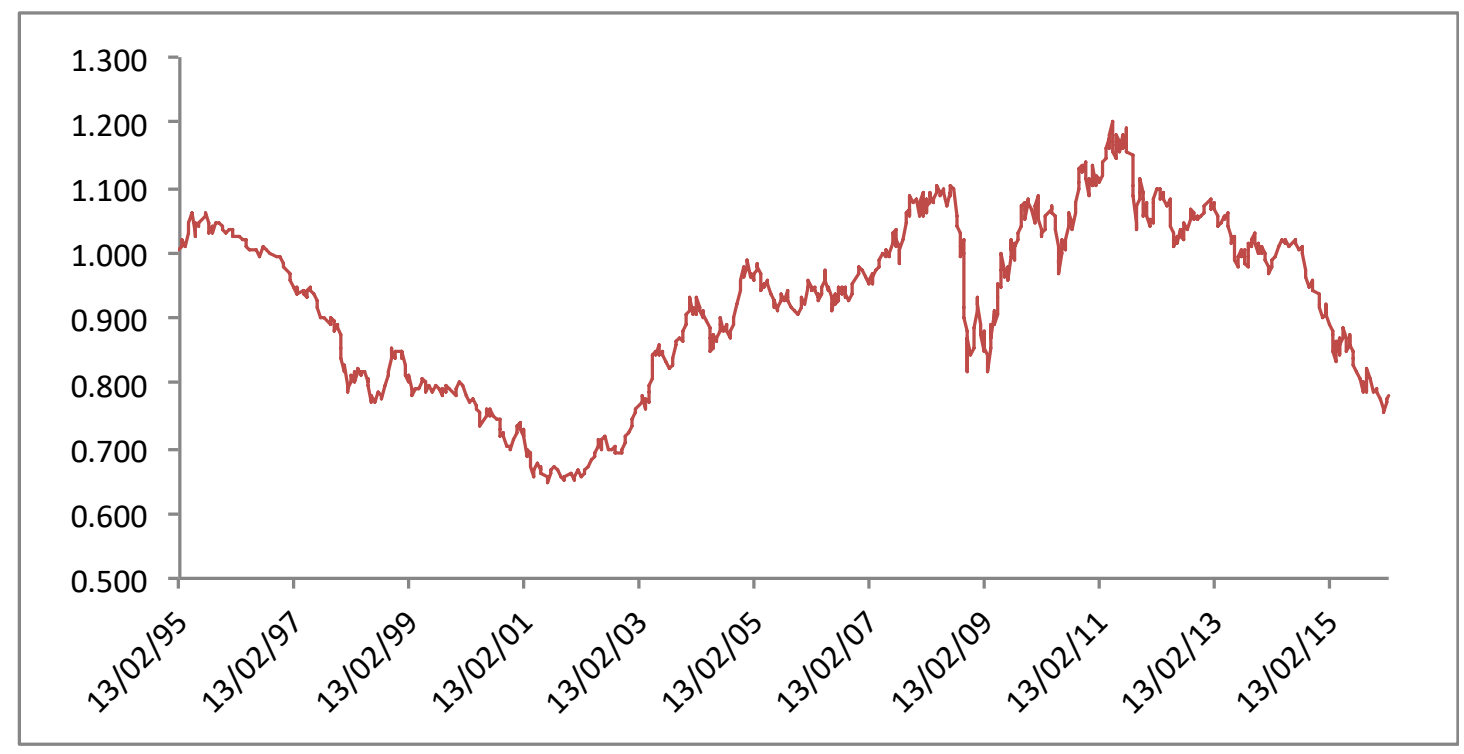

Notes: The figure plots the ratio of the USD price of gold to the nominal gold price index estimated using the principal components model given by Equations (13) and (14). Both series are based to 100 on 13 February 1995. 
Panel A: Eigenvectors

$\begin{array}{lcccc} & \text { PC1 } & \text { PC2 } & \text { PC3 } & \text { PC4 } \\ \text { AUD } & 0.134 & 0.452 & 0.053 & -0.030 \\ \text { BRL } & 0.142 & 0.323 & -0.078 & -0.091 \\ \text { CAD } & 0.213 & 0.236 & -0.040 & -0.130 \\ \text { CHF } & 0.113 & -0.053 & 0.655 & -0.071 \\ \text { CNY } & 0.289 & -0.152 & -0.053 & -0.045 \\ \text { EGP } & 0.259 & -0.143 & -0.051 & -0.045 \\ \text { EUR } & 0.125 & 0.090 & 0.615 & -0.146 \\ \text { GHS } & 0.209 & -0.130 & -0.084 & -0.037 \\ \text { HKD } & 0.290 & -0.158 & -0.063 & -0.047 \\ \text { IDR } & 0.108 & 0.141 & 0.002 & 0.647 \\ \text { INR } & 0.254 & 0.047 & -0.064 & -0.026 \\ \text { JPY } & 0.177 & -0.180 & 0.303 & 0.167 \\ \text { KRW } & 0.150 & 0.233 & -0.030 & 0.440 \\ \text { MXN } & 0.209 & 0.230 & -0.168 & -0.081 \\ \text { PEN } & 0.274 & -0.069 & -0.079 & -0.068 \\ \text { PGK } & 0.201 & -0.104 & -0.008 & -0.003 \\ \text { RUB } & 0.062 & 0.049 & -0.134 & -0.310 \\ \text { SAR } & 0.290 & -0.170 & -0.057 & -0.042 \\ \text { THB } & 0.212 & 0.021 & 0.039 & 0.385 \\ \text { TRY } & 0.122 & 0.324 & 0.014 & -0.148 \\ \text { USD } & 0.290 & -0.167 & -0.064 & -0.042 \\ \text { VND } & 0.275 & -0.158 & -0.074 & -0.037 \\ \text { ZAR } & 0.114 & 0.416 & 0.046 & -0.134\end{array}$

Panel B: Eigenvalues and Proportion of Variance Explained

$\begin{array}{lcccc} & \text { PC1 } & \text { PC2 } & \text { PC3 } & \text { PC4 } \\ \text { Eigenvalue } & 10.703 & 2.163 & 1.627 & 1.309 \\ \text { Proportion } & 46.53 \% & 9.41 \% & 7.07 \% & 5.69 \% \\ \text { Cumulative } & 93.06 \% & 55.94 \% & 63.01 \% & 68.70 \%\end{array}$

Notes: The table reports the results of principal components analysis applied to the sample of 23 real exchange rates against the GBP, measured in logarithmic first differences. Panel A reports the eigenvectors of the first four principal components. Panel B reports the eigenvalues, proportion of variance explained and the cumulative proportion of variance explained for the first four principal components. The data are measured weekly over the period 13 February 1995 to 23 February 2016. 
Table 2: Correlation Matrix

\begin{tabular}{|c|c|c|c|c|c|c|c|c|c|c|c|c|c|c|c|c|}
\hline & $\underset{\infty}{\stackrel{Z}{0}}$ & 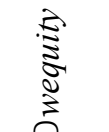 & $\begin{array}{l}\dddot{Z} \\
\mathbb{0} \\
3\end{array}$ & $\tilde{\sigma}$ & 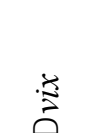 & 㲾 & 号 & 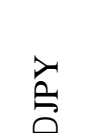 & 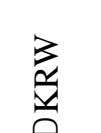 & $\underset{\sim}{\infty}$ & 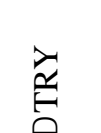 & 窝 & $\bar{U}$ & $\tilde{Q}$ & $\tilde{0}$ & ¿ \\
\hline gold & 1.00 & & & & & & & & & & & & & & & \\
\hline wequity & -0.13 & 1.00 & & & & & & & & & & & & & & \\
\hline wbond & 0.01 & -0.37 & 1.00 & & & & & & & & & & & & & \\
\hline oil & 0.05 & 0.05 & -0.02 & 1.00 & & & & & & & & & & & & \\
\hline$v i x$ & 0.02 & -0.69 & 0.46 & -0.02 & 1.00 & & & & & & & & & & & \\
\hline AUD & 0.31 & 0.26 & -0.51 & 0.01 & -0.32 & 1.00 & & & & & & & & & & \\
\hline EUR & 0.32 & -0.16 & 0.12 & -0.07 & 0.06 & 0.30 & 1.00 & & & & & & & & & \\
\hline JPY & 0.30 & -0.19 & 0.44 & -0.02 & 0.18 & 0.13 & 0.36 & 1.00 & & & & & & & & \\
\hline KRW & 0.15 & 0.11 & -0.34 & -0.02 & -0.17 & 0.38 & 0.15 & 0.26 & 1.00 & & & & & & & \\
\hline RUB & 0.04 & 0.13 & -0.03 & 0.02 & -0.11 & 0.12 & 0.06 & 0.01 & 0.07 & 1.00 & & & & & & \\
\hline TRY & 0.14 & 0.09 & -0.40 & -0.09 & -0.25 & 0.35 & 0.24 & 0.11 & 0.23 & 0.09 & 1.00 & & & & & \\
\hline USD & 0.24 & -0.01 & 0.17 & 0.01 & 0.04 & 0.25 & 0.30 & 0.56 & 0.36 & 0.18 & 0.28 & 1.00 & & & & \\
\hline $\mathrm{PC} 1$ & 0.32 & 0.05 & -0.01 & 0.00 & -0.07 & 0.44 & 0.41 & 0.58 & 0.49 & 0.20 & 0.40 & 0.95 & 1.00 & & & \\
\hline $\mathrm{PC} 2$ & 0.14 & 0.31 & -0.82 & -0.02 & -0.46 & 0.66 & 0.13 & -0.26 & 0.34 & 0.07 & 0.48 & -0.25 & 0.00 & 1.00 & & \\
\hline PC3 & 0.27 & -0.35 & 0.27 & -0.09 & 0.23 & 0.07 & 0.78 & 0.39 & -0.04 & -0.17 & 0.02 & -0.08 & 0.00 & 0.00 & 1.00 & \\
\hline PC4 & -0.01 & -0.10 & -0.11 & 0.00 & 0.04 & -0.03 & -0.17 & 0.19 & 0.50 & -0.35 & -0.17 & -0.05 & 0.00 & 0.00 & 0.00 & 1.00 \\
\hline
\end{tabular}

Notes: The table reports the correlation of the price of gold, the fundamental variables, the subset of seven exchange rates and the first four principal components of the full set of 23 exchange rates, all measured in logarithmic differences. The data are measured weekly over the period 13 February 1995 to 23 February 2016. 


$\begin{array}{lcccc} & \text { Mean } & \text { S.D. } & \text { Min } & \text { Max } \\ \text { gold } & 0.078 \% & 2.359 \% & -14.740 \% & 12.321 \% \\ \text { wequity } & 0.059 \% & 2.080 \% & -11.069 \% & 8.632 \% \\ \text { wbond } & 0.068 \% & 1.069 \% & -6.685 \% & 7.197 \% \\ \text { oil } & 0.035 \% & 4.302 \% & -25.995 \% & 16.093 \% \\ \text { vix } & 0.050 \% & 12.703 \% & -40.954 \% & 114.072 \% \\ \text { AUD } & 0.017 \% & 1.598 \% & -8.907 \% & 8.786 \% \\ \text { BRL } & -0.035 \% & 2.249 \% & -23.858 \% & 7.266 \% \\ \text { CAD } & 0.008 \% & 1.327 \% & -5.119 \% & 7.124 \% \\ \text { CHF } & 0.005 \% & 1.430 \% & -9.898 \% & 14.910 \% \\ \text { CNY } & 0.040 \% & 1.251 \% & -5.152 \% & 9.855 \% \\ \text { EGP } & 0.035 \% & 1.440 \% & -17.783 \% & 9.957 \% \\ \text { EUR } & -0.008 \% & 1.115 \% & -4.373 \% & 6.044 \% \\ \text { GHS } & -0.027 \% & 1.845 \% & -8.139 \% & 14.383 \% \\ \text { HKD } & 0.006 \% & 1.251 \% & -5.549 \% & 10.394 \% \\ \text { IDR } & -0.012 \% & 3.519 \% & -35.396 \% & 38.762 \% \\ \text { INR } & 0.032 \% & 1.352 \% & -6.976 \% & 8.767 \% \\ \text { JPY } & -0.039 \% & 1.901 \% & -8.329 \% & 18.732 \% \\ \text { KRW } & -0.012 \% & 2.013 \% & -19.080 \% & 17.752 \% \\ \text { MXN } & 0.020 \% & 1.771 \% & -10.401 \% & 9.603 \% \\ \text { PEN } & 0.001 \% & 1.341 \% & -6.082 \% & 8.421 \% \\ \text { PGK } & 0.027 \% & 1.881 \% & -11.841 \% & 15.901 \% \\ \text { RUB } & 0.036 \% & 5.057 \% & -76.299 \% & 104.087 \% \\ \text { SAR } & 0.013 \% & 1.255 \% & -5.327 \% & 10.852 \% \\ \text { THB } & -0.007 \% & 1.661 \% & -12.527 \% & 8.883 \% \\ \text { TRY } & 0.049 \% & 2.327 \% & -39.285 \% & 11.397 \% \\ \text { USD } & 0.013 \% & 1.241 \% & -5.241 \% & 10.024 \% \\ \text { VND } & 0.031 \% & 1.317 \% & -6.862 \% & 9.095 \% \\ \text { ZAR } & -0.049 \% & 2.063 \% & -11.369 \% & 9.342 \% \\ \text { PC1 } & 0.000 & 3.271 & -13.863 & 24.206 \\ \text { PC2 } & 0.000 & 1.471 & -10.454 & 10.178 \\ \text { PC3 } & 0.000 & 1.275 & -5.861 & 6.147 \\ \text { PC4 } & 0.000 & 1.144 & -12.632 & 10.494\end{array}$

Notes: The table reports the mean, standard deviation, minimum and maximum values of the price of gold, the fundamental variables, the exchange rates and the first three principal components of the exchange rates, all measured in logarithmic differences. The data are measured weekly over the period 13 February 1995 to 23 February 2016. 
Panel A: Estimated Cointegrating Vector

\begin{tabular}{|c|c|c|c|c|c|}
\hline & (1) & (2) & $r$ & $F$ & (5) \\
\hline \multirow[t]{2}{*}{ wequity } & -0.096 & -0.406 & -0.325 & -0.228 & -0.236 \\
\hline & $(0.024)$ & $(0.012)$ & $(0.016)$ & $(0.024)$ & $(0.024)$ \\
\hline \multirow[t]{2}{*}{ wbond } & -1.464 & -1.025 & -0.819 & -0.818 & -0.895 \\
\hline & (0.067) & $(0.039)$ & $(0.047)$ & $(0.046)$ & $(0.048)$ \\
\hline \multirow[t]{2}{*}{ oil } & -0.089 & 0.064 & 0.011 & 0.024 & 0.034 \\
\hline & $(0.011)$ & $(0.010)$ & $(0.012)$ & $(0.012)$ & $(0.012)$ \\
\hline \multirow[t]{2}{*}{$v i x$} & 0.115 & 0.061 & 0.070 & 0.079 & 0.069 \\
\hline & (0.009) & (0.009) & $(0.009)$ & $(0.009)$ & $(0.009)$ \\
\hline \multirow[t]{2}{*}{ AUD } & 0.479 & & & & \\
\hline & $(0.050)$ & & & & \\
\hline \multirow[t]{2}{*}{ EUR } & 0.179 & & & & \\
\hline & $(0.059)$ & & & & \\
\hline \multirow[t]{2}{*}{ JPY } & 0.636 & & & & \\
\hline & $(0.036)$ & & & & \\
\hline \multirow[t]{2}{*}{ KRW } & -0.192 & & & & \\
\hline & $(0.036)$ & & & & \\
\hline \multirow[t]{2}{*}{ RUB } & 0.157 & & & & \\
\hline & $(0.021)$ & & & & \\
\hline \multirow[t]{2}{*}{ TRY } & -0.142 & & & & \\
\hline & $(0.025)$ & & & & \\
\hline \multirow[t]{2}{*}{ USD } & 0.165 & & & & \\
\hline & $(0.062)$ & & & & \\
\hline \multirow[t]{2}{*}{ PC1 } & & 0.469 & 0.517 & 0.510 & 0.499 \\
\hline & & $(0.011)$ & $(0.012)$ & $(0.012)$ & $(0.012)$ \\
\hline \multirow[t]{2}{*}{$\mathrm{PC} 2$} & & & 0.317 & 0.279 & 0.201 \\
\hline & & & $(0.042)$ & $(0.042)$ & $(0.044)$ \\
\hline \multirow[t]{2}{*}{ PC3 } & & & & 0.275 & 0.321 \\
\hline & & & & $(0.052)$ & $(0.052)$ \\
\hline \multirow[t]{2}{*}{ PC4 } & & & & & -0.196 \\
\hline & & & & & $(0.037)$ \\
\hline \multirow[t]{2}{*}{ trend } & 0.002 & 0.002 & 0.001 & 0.001 & 0.001 \\
\hline & $(0.000)$ & $(0.000)$ & $(0.000)$ & $(0.000)$ & $(0.000)$ \\
\hline \multirow[t]{2}{*}{ constant } & 8.781 & 6.158 & 5.113 & 4.695 & 4.998 \\
\hline & $(0.313)$ & $(0.119)$ & $(0.180)$ & $(0.194)$ & $(0.200)$ \\
\hline
\end{tabular}




\section{Panel B: Cointegration Test}

\begin{tabular}{|c|c|c|c|c|c|}
\hline & (1) & $r$ & $r$ & $r$ & $\mathbf{r}$ \\
\hline$Z$-statistic & -6.320 & -5.423 & -5.595 & -5.538 & -5.501 \\
\hline $1 \%$ & -6.885 & -5.545 & -5.796 & -6.035 & -6.261 \\
\hline $5 \%$ & -6.348 & -5.001 & -5.254 & -5.494 & -5.722 \\
\hline $10 \%$ & -6.067 & -4.717 & -4.971 & -5.211 & -5.440 \\
\hline
\end{tabular}

Notes: The table reports the results of the Engle-Granger test for cointegration using the model given by Equation (13). Panel A reports the estimated cointegrating vector with the coefficient on the gold price normalized to unity. $\Sigma \mathrm{PC} 1-\Sigma \mathrm{PC} 4$ are the cumulative values of the first four principal components of the log change in the exchange rates. The cointegrating vector is estimated by OLS over the sample period 13 February 1995 to 23 February 2016. Standard errors are in parentheses. Panel B reports the Z-statistic to test the null hypothesis of no cointegration, and the 1\%,5\% and 10\% critical values calculated by MacKinnon (2010). The coefficients and standard errors for the cumulative principal components have been multiplied by 100 . 


\begin{tabular}{|c|c|c|c|c|c|c|}
\hline \multirow[b]{2}{*}{ wequity } & \multicolumn{2}{|c|}{ (1) } & \multicolumn{2}{|c|}{$\bar{F} \quad$ (2) } & \multicolumn{2}{|c|}{$\bar{F} \quad(3)$} \\
\hline & $-0.227 * * *$ & $(0.043)$ & $-0.222 * * *$ & $(0.043)$ & $-0.153^{* * *}$ & $(0.050)$ \\
\hline wbond & -0.046 & $(0.110)$ & 0.006 & $(0.091)$ & $0.422 * * *$ & $(0.140)$ \\
\hline oil & $0.037 * *$ & $(0.015)$ & $0.038 * * *$ & $(0.015)$ & $0.049 * * *$ & $(0.015)$ \\
\hline$v i x$ & -0.012 & $(0.007)$ & -0.011 & $(0.007)$ & -0.004 & $(0.009)$ \\
\hline AUD & $0.402 * * *$ & $(0.056)$ & $0.407 * * *$ & $(0.063)$ & & \\
\hline EUR & $0.321 * * *$ & $(0.066)$ & $0.317 * * *$ & $(0.062)$ & & \\
\hline JPY & $0.213 * * *$ & $(0.050)$ & $0.199 * * *$ & $(0.054)$ & & \\
\hline KRW & -0.024 & $(0.039)$ & 0.000 & - & & \\
\hline RUB & 0.005 & $(0.013)$ & 0.005 & $(0.009)$ & & \\
\hline TRY & -0.022 & $(0.034)$ & 0.000 & - & & \\
\hline USD & 0.089 & $(0.068)$ & 0.073 & $(0.065)$ & & \\
\hline $\mathrm{PC} 1$ & & & & & $0.241 * * *$ & $(0.025)$ \\
\hline $\mathrm{PC} 2$ & & & & & $0.535 * * *$ & $(0.092)$ \\
\hline PC3 & & & & & $0.343 * * *$ & $(0.065)$ \\
\hline PC4 & & & & & 0.022 & $(0.051)$ \\
\hline$E C M_{t-1}$ & $-0.046 * * *$ & (0.009) & $-0.046 * * *$ & $(0.009)$ & $-0.041 * * *$ & $(0.010)$ \\
\hline Constant & $0.000 * * *$ & $F \quad(0.000)$ & 0.001 & $(0.001)$ & 0.001 & $(0.001)$ \\
\hline$R^{2}$ & 0.227 & & 0.227 & & 0.245 & \\
\hline 2 & $\quad 0.984$ & & 1.000 & & - & \\
\hline AR1 p-value & 0.189 & & 0.181 & & 0.171 & \\
\hline Het p-value & 0.739 & & 0.771 & & 0.835 & \\
\hline
\end{tabular}

Notes: The table reports the estimated error correction model given by Equation (14) for the reduced sample of seven currencies (Column 1), the reduced sample of seven currencies with the constraint that the coefficients on the exchange rate changes are non-negative and sum to unity (Column 2) and the first four principal components of the full set of 23 exchange rates (Column 3). The model is estimated over the sample period 13 February 1995 to 23 February 2016 by OLS (Columns 1 and 3) or NLS (Column 2). Standard errors are in parentheses. ' $* * *$ ', '**' and ' $*$ ' represent statistical significance at the $1 \%, 5 \%$ and $10 \%$ level, respectively. $\Sigma \beta_{2}$ is the sum of the coefficients on the exchange rate terms. 'AR1 $\mathrm{p}$-value' is the p-value for the Breusch-Godfrey test of the null hypothesis of no first order serial correlation. 'Het pvalue' is the p-value for the Breusch-Pagan test of the null hypothesis of no heteroscedasticity. 


\section{Gold price index USD gold price}

$\begin{array}{lcc}\text { Mean } & 0.13 \% & 0.11 \% \\ \text { St. Dev } & 2.16 \% & 2.38 \% \\ \text { Minimum } & -14.82 \% & -14.50 \% \\ \text { Maximum } & 11.38 \% & 14.12 \%\end{array}$

Correlation with:

$\begin{array}{lcc}\text { USD gold price } & 0.853^{* * *} & 1.000 \\ \text { wequity } & -0.218^{* * *} & 0.082^{* * * *} \\ \text { wbond } & 0.120^{* * *} & 0.387^{\text {*** }} \\ \text { oil } & 0.046 & 0.155^{* * *} \\ \text { vix } & 0.155^{* * *} & -0.001\end{array}$

Notes: The table reports summary statistics for the returns of the nominal gold price index and the USD gold price, including the mean, standard deviation, minimum and maximum, and correlations with the USD price of gold, the world equity index, the world bond index, the oil price and the VIX index. The world equity and bond indices and the oil price are measured in USD. The sample period is 13 February 1995 to 23 February 2016. '***', '**' and '*' represent statistical significance at the $1 \%, 5 \%$ and $10 \%$ level, respectively. 
Table 7 Estimated Error Correction Model (Sub-Periods)

\begin{tabular}{|c|c|c|c|c|c|c|}
\hline \multirow[b]{2}{*}{ wequity } & \multicolumn{2}{|c|}{$13 / 02 / 95-11 / 02 / 02$} & \multicolumn{2}{|c|}{ 18/02/02-16/02/09 } & \multicolumn{2}{|c|}{$23 / 02 / 09-22 / 02 / 16$} \\
\hline & 0.013 & $(0.061)$ & -0.040 & $(0.079)$ & $-0.449 * * *$ & $(0.092)$ \\
\hline wbond & 0.011 & $(0.184)$ & 0.131 & $(0.255)$ & $0.453^{* *}$ & $(0.189)$ \\
\hline oil & $0.037 *$ & $(0.019)$ & $0.048^{*}$ & $(0.026)$ & $0.083 * * *$ & $(0.030)$ \\
\hline$v i x$ & -0.003 & $(0.012)$ & 0.006 & $(0.015)$ & $-0.022 *$ & $(0.011)$ \\
\hline $\mathrm{PC} 1$ & $0.287 * * *$ & $(0.031)$ & $0.159 * * *$ & $(0.039)$ & $0.295 * * *$ & $(0.036)$ \\
\hline $\mathrm{PC} 2$ & $0.218 *$ & $(0.117)$ & $0.349^{* *}$ & $(0.149)$ & $0.554 * * *$ & $(0.129)$ \\
\hline PC3 & $0.290 * * *$ & $(0.073)$ & $0.809 * * *$ & $(0.127)$ & $0.311 * * *$ & $(0.103)$ \\
\hline $\mathrm{PC} 4$ & -0.003 & $(0.055)$ & -0.232 & $(0.229)$ & $0.906 * * *$ & $(0.309)$ \\
\hline$E C M_{t-1}$ & $-0.116 * * *$ & $(0.026)$ & $-0.118 * * *$ & $(0.026)$ & $-0.144 * * *$ & $(0.026)$ \\
\hline Constant & 0.000 & $(0.001)$ & 0.001 & $(0.001)$ & 0.001 & $(0.001)$ \\
\hline$R^{2}$ & 0.315 & & 0.293 & & 0.341 & \\
\hline $\mathrm{N}$ & 365 & & 365 & & 365 & \\
\hline AR1 p-value & 0.002 & & 0.081 & & 0.253 & \\
\hline Het p-value & 0.404 & & 0.568 & & 0.245 & \\
\hline EG Z-statistic & -5.263 & & $-6.409 * * *$ & & $-7.058 * * *$ & \\
\hline
\end{tabular}

Notes: The table reports the estimated error correction model given by Equation (14) using the first four principal components of the full set of 23 exchange rates. The model is estimated over three sub periods: 13 February 1995 to 11 February 2002 (Column 1), 18 February 2002 to 16 February 2009 (Column 2) and 23 February 2009 to 22 February 2016 (Column 3). The model is estimated by OLS. Standard errors are in parentheses. '***', '**' and '*' represent statistical significance at the $1 \%, 5 \%$ and $10 \%$ level, respectively. 'AR1 p-value' is the pvalue for the Breusch-Godfrey test of the null hypothesis of no first order serial correlation. 'Het p-value' is the p-value for the Breusch-Pagan test of the null hypothesis of no heteroscedasticity. 'EG Z-statistic' is the Z-statistic to test the null hypothesis of no cointegration in the Engle-Granger first stage regression. 